\title{
Overall Layout Design of Iron and Steel Plants Based on SLP Theory
}

\author{
Ermin Zhou, Kelou Chen, and Yanrong Zhang \\ School of mechanical and electrical engineering, East china jiaotong University, \\ Nanchang, China
}

\begin{abstract}
Based on the total production process of iron and steel plant, and with the general design requirements for the major operating units, the major operating sites' overall layout relationship of the iron and steel plant is determined. Based on the production workshops, auxiliary plants, power plants, transportation facilities, the functions of departments, subsidiary production and living services departments' within and outside association, the situation of materials' into and out, systematic optimization layout planning is proposed. With the size and position relationship of the operating units, and other relative limiting condition and common practices, overall layout design of the factory is developed.
\end{abstract}

Keywords: Systematic layout planning, SLP, Iron and steel plant, Overall layout.

\section{Introduction}

Many steel companies in China are currently conducting or planning a new expansion of production base, for the internal and external logistics of steel plant are volume, and the status of a serious lack of iron ore, scientific selection of the steel plant site, rational distribution of the various operating units. To find the best spatial location of all facilities for the plant, the enterprise's materials, equipment and human resources are efficiently used, improve the utilization of various resources, to make the most productive, to catch up with the trend of China's iron and steel enterprises development and to fulfill the requirements of a large number of imported iron ore and the special region development.

\section{The Work Sites Overall Layout of Iron and Steel Plants}

\subsection{The Principle of Overall Layout of Iron and Steel Plants}

Site in the established arrangement of plants within the various venues, to adapt to urban planning and industrial development zone request, local natural conditions combined rational use of land, fully arranged in various venues, and create synergies. (1) to adapt to urban planning; (2) the rational use of land; (3) The arrangements 
for venues; (4) to create collaborative conditions; (5) the effective protection of the environment.

\subsection{The Design Requirements of the Major Operating Units}

(1) Production areas (plant): iron and steel plant production area is the main part of the overall layout, should give priority to select the appropriate location. According to the nature of the steel production plant, A larger percentage of transportation outside the factory, so should close to interface points of the main mode of transportation outside the factory: stations, terminals, roads in the vicinity; production area is large consumption of water and electricity facilities, should close to the water supply and Power supply; Production areas are also produced pollution venue, should be installed in the minimum space required frequency of clean wind upwind side; around the production area may be set aside for the development of room for expansion.

(2) Transport Facilities Location: When using the waterway transport outside the factory, we must select the appropriate to the domestic terminal building sites, particularly the use of raw materials for large ships dock, to be near the production area, and a reasonable convergence conditions. As much as possible make the unloading of materials directly to the production areas, finished packing can be directly transported to the terminal. When use the rail transportation, Should on the basis of convergence conditions, logistics direction, working conditions of the transfer, to select a similar size of the marshalling factories, should leaves the factory to the possible expansion of the scale synchronization. Production areas and cities, terminals, stations, water sources, sewage treatment plants, substations, residue field, construction site, residential sites and adjacent areas such as enterprise collaboration should be roads.

(3) Water and power facilities: the water sources of iron and steel plants are mainly come from the natural water sources such as river or sea. Either surface or groundwater sources, if used as domestic water, should leaves health protection regulations required distance to prevent pollution. Sewage treatment plant should layout in the direction of water discharge, close to the water into point. Treated sewage discharge outlet should be located downstream of water points, and has more than $100 \mathrm{~m}$ from the health protection.

(4) Health Protection belt: between steel mill plant and other sites or adjacent enterprises, according to the concentration of pollutants emitted by factories, according to local environmental assessment requirements set a certain width of the area of health protection. In the zone, according to functional requirements for green, light pollution, the facilities can be arranged, but not often live in housing arranged.

(5) Java games: slag and industrial waste disposal sites should be selected in the main plant slag and industrial waste discharge direction, make full use of lowlying land, wasteland, valley and beach land. Stockpiling sites may require unified planning, acquisition phases, the stockpiles of the early stage generally not less than 10 years. Slag and industrial waste should be fully comprehensive utilization, save resources, reduce the impact of keeping occupied land, which is the trend of development.

(6) Residential area: subject to health protection standards and does not affect plant development, should close the factory layout. Between residential areas and the 
plant should not be arranged the railway and busy highways, residential roads across the region can not be transited, between neighboring cities, passenger stations, terminals and the plant should be roads.

(7) Construction Site: construction site set up for the construction of various facilities. Therefore, its location should choose the fixed end of the factory building, and plant a certain distance between the left does not affect plant development. To facilitate the use of permanent rail, road, water, electricity and other facilities.[2]

Based on the above basic principles and general layout of the design requirementsof the major operating units, combined with Baosteel Zhanjiang New Area in the special conditions and the geographical situation of the factory location, environmental factors, to determine the overall layout of the various sites on the iron and steel plant, shown in figure 1.

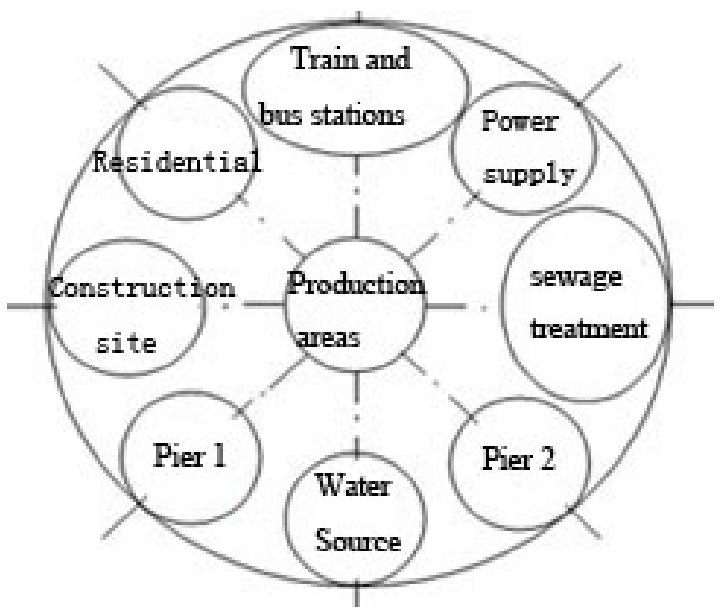

Fig. 1. Steel plant general layout diagram of venues

\section{Systematic Layout Planning of Iron and Steel Plant}

\subsection{SLP Method Introduction}

Systematic Layout Planning was proposed by Richard • Muther of American, and had been widely used. This approach applies not only to the factory layout design and production systems, also can be used for logistics centers, shops, hospitals, schools, and other service facilities layout design [3]. When the SLP method is applied to the overall layout of industrial facilities design, commonly used procedure is to analyze the relationship between production process, and then the logistics of the operation unit and non-flow analysis, and make a weight, to obtain a comprehensive relationship between them, Finally, according to the intensity of the various operating units draw their location diagram. 


\subsection{Production Process}

In the iron and steel plant, supply of raw materials and fuel from raw materials prepared workshops to the sinter plant and coking plant workshop, Produced sinter and coke been supplied to the iron workshop, supply the production of hot metal to steel-making plant, supply the liquid steel continuous to casting plant, supply the production of steel ingot to steel rolling plant, Shipped out the production of finished steel products, form of the whole plant production processes. The relationship between the workshop is the production process relations, we must keep this process, in general can not be changed.

\subsection{Logistics Relations (Quantitative Relations)}

The design according to an annual output of 10 million tons of steel to consider, according to the scale of production, material consumption indicators and quality of materials to calculate the materials number of input and output. According to the quantity of material flow between the production plants, power plants, ancillary facilities, residential areas, establish the material flow start and end table, letters on behalf of the workshop(A-Raw material, B-Sintering, C -Coking, D-Iron, E -Steel, FRolling, G- Thermoelectricity, H-Oxygen, I- Gas, J- Substation, K- Region, L- Residential), show in table 1.

Table 1. Material flow start and end table (ten thousands tons / year)

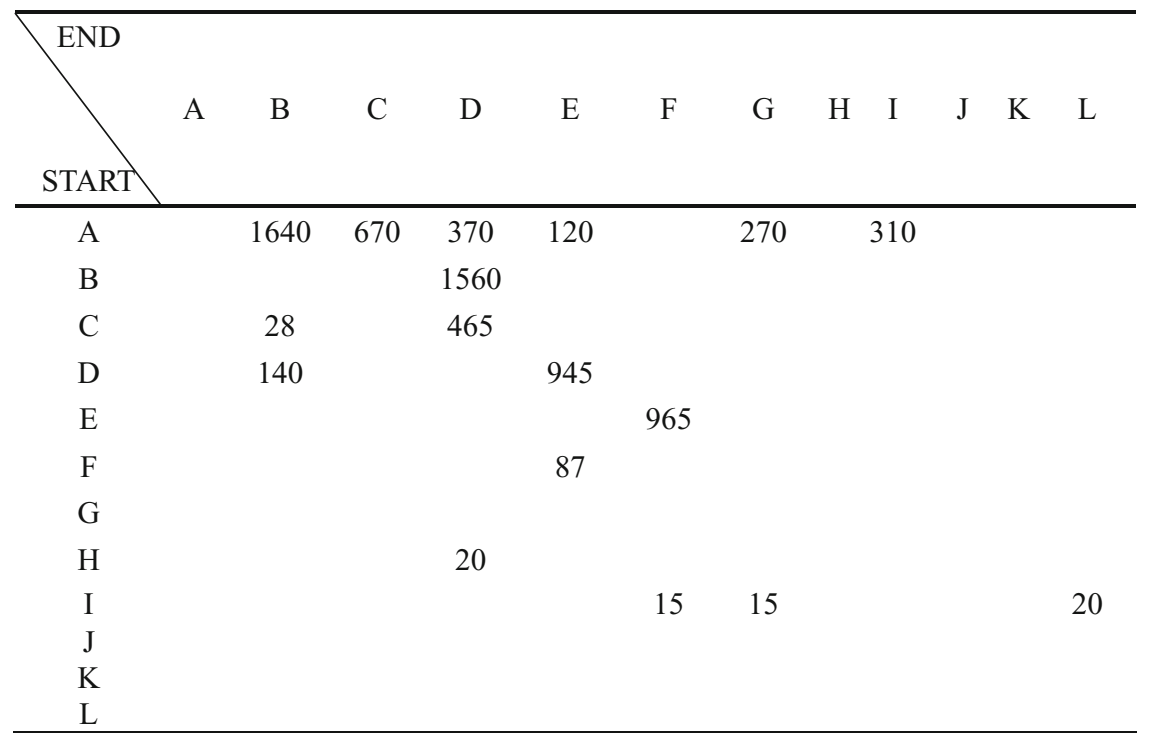

According to material flow start and end table, according to the amount of the whole plant logistics distribution, material flow can be divided into six relations level, show in table 2 . 
Table 2. Material flow classification table

\begin{tabular}{|c|c|c|c|}
\hline $\begin{array}{l}\text { Serial } \\
\text { number }\end{array}$ & \multicolumn{2}{|c|}{$\begin{array}{l}\text { Material flow (ten thousands tons } \\
\text { / year) }\end{array}$} & $\begin{array}{c}\text { Relationship } \\
\text { level }\end{array}$ \\
\hline 1 & Largest logistics & $>1000$ & A \\
\hline 2 & Large logistics & $600 \sim 1000$ & $\mathrm{E}$ \\
\hline 3 & $\begin{array}{l}\text { Logistics moderate } \\
\text { amount of }\end{array}$ & $300 \sim 600$ & I \\
\hline 4 & $\begin{array}{l}\text { Logistics small } \\
\text { amount of }\end{array}$ & $50 \sim 300$ & $\mathrm{O}$ \\
\hline 5 & Logistics less & $<50$ & $\mathrm{U}$ \\
\hline 6 & $\begin{array}{l}\text { No amount of } \\
\text { logistics }\end{array}$ & 0 & X \\
\hline
\end{tabular}

According to material flow start and end table and material flow classification table, set out the logistics amount, material name and relationship level between the workshop, and then according to the logistics amount and the relationship level, drawn logistics relationship diagram, shown in Figure 2. From the logistics relationship diagram can be seen the relationship level of each workshop, just the proximity degree, and as a basis for layout.

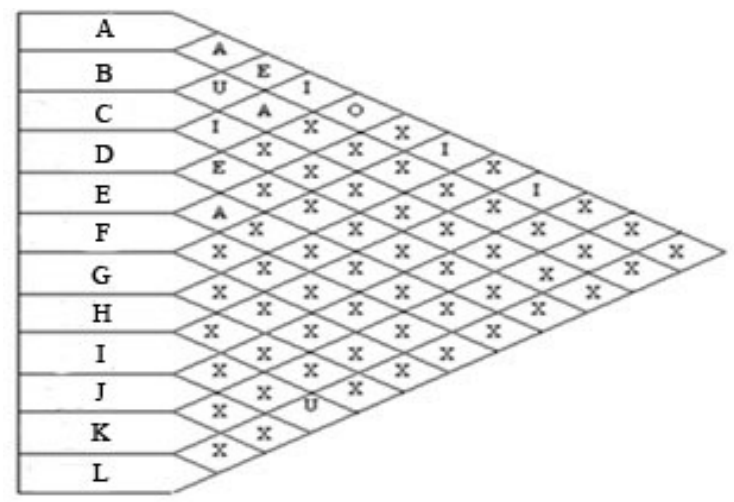

Fig. 2. Logistics relationship diagram

\subsection{Non-logistics Relationship}

Steel plant is basically the non-logistics relationships are the following: (1) interference of environmental pollution; (2) security aspects, such as fire, explosions, and traffic accidents, etc.; (3) Energy supply and demand requirements; (4) ease of production management, as the case may change.

Relationship between level of non-logistics division, according to the qualitative factors identified above, need to study in detail the relationship between the various workshops, in accordance with the hierarchy of importance of the relationship, show in table 3 . 
Table 3. Non-logistics relationship levels

\begin{tabular}{|c|c|c|}
\hline $\begin{array}{l}\text { Nature of the } \\
\text { relationship }\end{array}$ & $\begin{array}{l}\text { Relationsh } \\
\text { ip level }\end{array}$ & Explain \\
\hline $\begin{array}{c}\text { Absolutely necessary to } \\
\text { close }\end{array}$ & $\mathrm{A}$ & Consider merger \\
\hline specially needs to close & $\mathrm{E}$ & Requirement to close \\
\hline Need to close & I & Demand to close \\
\hline Generally to close & $\mathrm{O}$ & A certain distance \\
\hline Unimportant & $\mathrm{U}$ & Not limited to distance \\
\hline Do not need to close & $\mathrm{X}$ & $\begin{array}{l}\text { No relationship or } \\
\text { interference }\end{array}$ \\
\hline
\end{tabular}

Steel plant relations of non-logistics factors, just close to ground level, generally there are following several, show in table 4.

Table 4. Non-logistics relationship factors

\begin{tabular}{cc}
\hline Code & \multicolumn{2}{c}{ relations of non-logistics factors } \\
\hline 1 & The requirements of production management \\
& relations \\
2 & Power supply requirements \\
3 & Security and environmental protection \\
4 & Maintenance and support facilities requirements \\
\hline
\end{tabular}

According to Table 3, and the importance of their classified nature of relations between requirement levels, rendering non-logistics relationship diagram, shown in figure 3 .

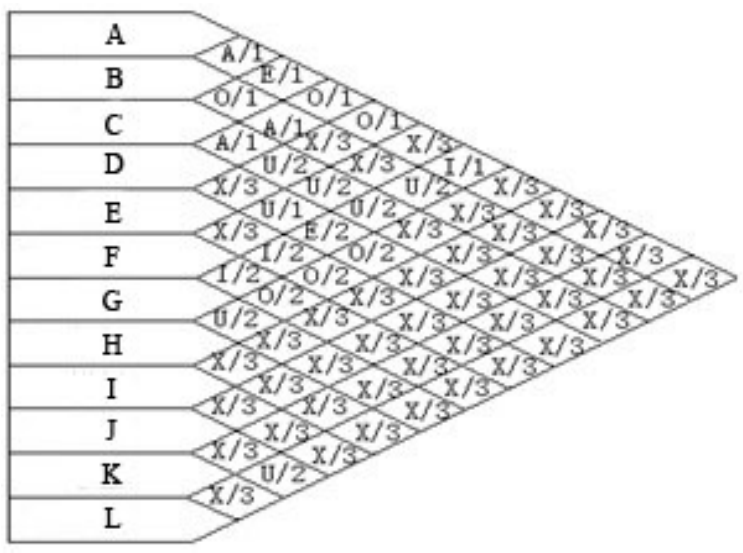

Fig. 3. Non-logistics relationship diagram 


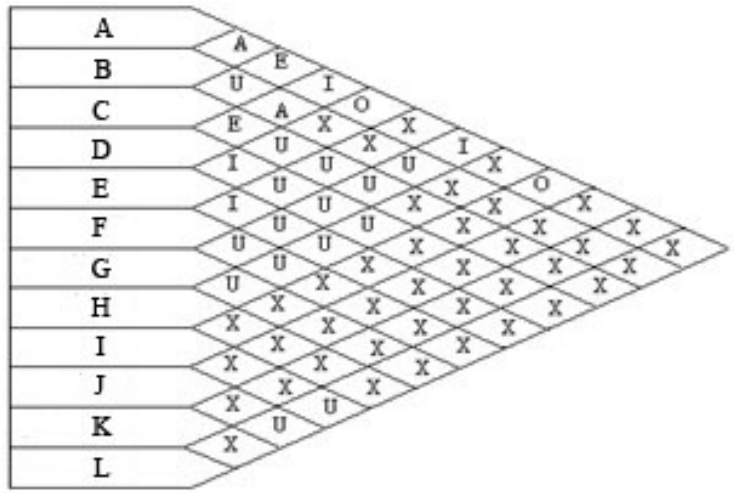

Fig. 4. Integrated relationship diagram

Table 5. Relations dense representation

\begin{tabular}{cccc}
\hline Level & Coefficient & Line express & Close degree \\
\hline $\mathrm{A}$ & 4 & $/ / / /$ & Absolutely necessary \\
$\mathrm{E}$ & 3 & $/ / /$ & Particularly important \\
$\mathrm{I}$ & 2 & $/ /$ & Important \\
$\mathrm{O}$ & 1 & $/$ & General \\
$\mathrm{U}$ & 0 & $\left.-\mathrm{N}_{-} \mathrm{tag}\right)$ & Unimportant \\
$\mathrm{X}$ & -1 & Unimportant or do not want to
\end{tabular}

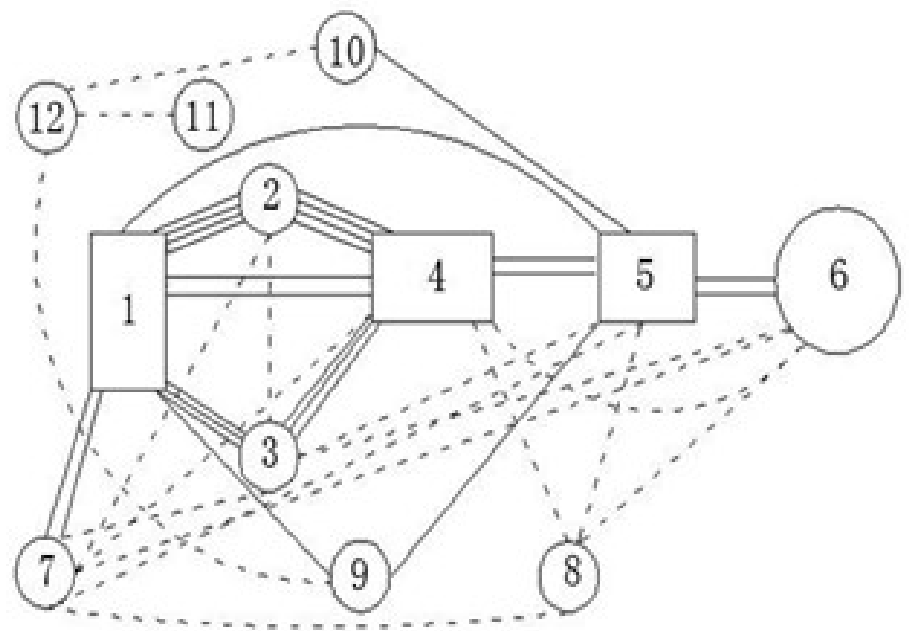

Fig. 5. The location-related map of operating units 


\subsection{Comprehensive Relationship}

The overall layout of the steel plant is main by the logistics relations, supplemented by non-logistics relationships, both to reduce operating costs, reduce production costs and ensure the safety and the environment clean. Considering the logistics relations and non-logistics relationship, to set the level values: $A=6, E=5, I=4, O=3, U=$ $2, X=1$; between the logistics relations and non-logistics relationship weight by $2: 1$ calculation; calculate the value of the integrated relationship and divide into six grades by size, A: 18, E: $14 \sim 17$, I: $11 \sim 13$, O: $8 \sim 10$, U: $4 \sim 7$, X 3, according to the calculated integrated relationship-level value and the relationship between their level, rendering comprehensive diagram, shown in figure 4.

By the more comprehensive relationship, the relationship between the operating units to use as shown in table 5 to determine the connection type, mapping the location of the various operating units of the relevant plan, shown in figure 5.

\section{Determine the Overall Layout of the Steel Plant}

\subsection{Determine the Area of Main Workshops}

Reference the range of available data from design department, accessibility to consider the development of space, roughly determine the plant land area of the main workshop of annual capacity of 10 million tons steel (with green and the surrounding road), show in table 6.

Table 6. The main workshop area of land (ten thousands m2)

\begin{tabular}{ccc}
\hline Serial number & Shop name & Area \\
\hline 1 & Materials workshop & 320 \\
2 & Sintering plant & 120 \\
3 & Coking plant & 180 \\
4 & Iron plant & 150 \\
5 & Steel workshop & 150 \\
6 & Rolling shop (plate, thread, & 300 \\
7 & tubes, wheel, etc.) & 80 \\
8 & Thermal power station & 20 \\
9 & Oxygen station & 40 \\
\hline
\end{tabular}

\subsection{The General Layout Plan to Determine}

The above analysis of various aspects, according to the main production plant and the operating relationship between the location of units, reference auxiliary plant, power plant, residential area, port, railway station interface, and finally determine the overall layout of the design of steel plant design, shown in figure 6. 


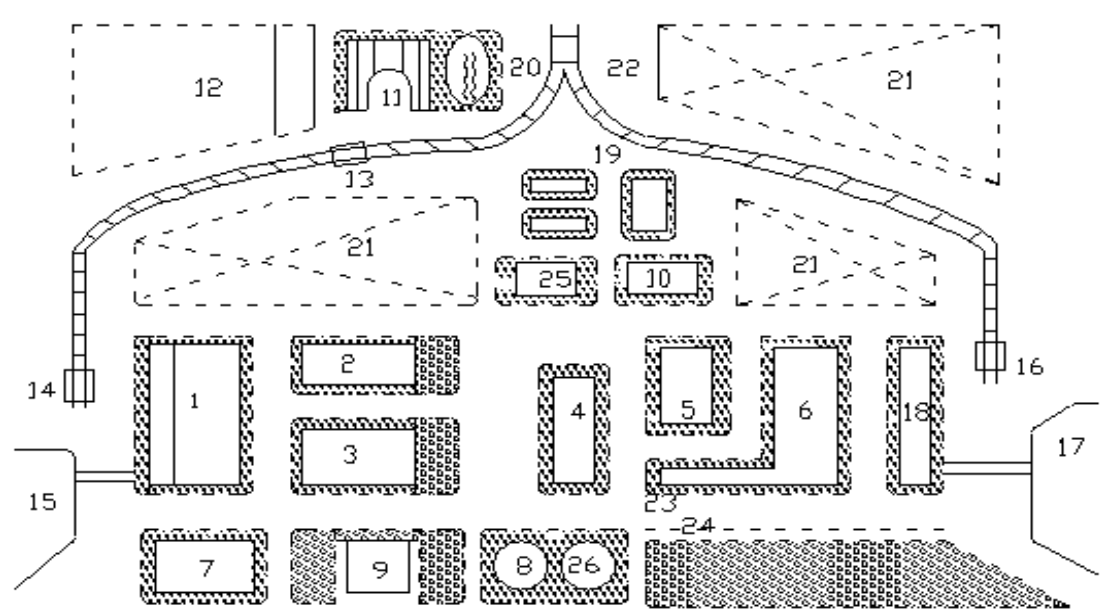

Fig. 6. The overall layout plan steel plant。 1-raw materials;2-sintering;3-Coking;4-iron;5steel;6-rolling;7-Thermal;8-Oxygen;9-gas; 10-Transmission;11-the total area;12-residential and commercial areas;13-Terminal;14-raw materials Station; 15-the entrance port;16-Trans Station;17-export terminal;18-finished products;19-Sports;20-artificial lake; 21-Development Reserve;22-Railway;23-lawn,flower beds, etc.; 24-bush;25-residue field;26-water station.

\section{Summary}

Due to the large flow of materials in steel plant, logistics factors in the overall layout design accounts for a large proportion, therefore, this design started centers around the steel mills logistics factor. From the operating unit focused on the logistics relationship and both of non-logistics relationships, obtained comprehensive relations, and by the operating unit of area, green requirements to make the overall layout plan steel plant. Emphasis analyzed from the two aspects of logistics and non-logistics relationship between the various operating units, obtained comprehensive relations, and by the operating unit of area, green requirements to make the overall layout plan of steel plant. The overall layout of the steel plant is difficult to achieve perfection, for the specific internal and external conditions, natural and geographical factors and regional development, etc. Harmful gases and waste water is also not possible have no blunder, more serious pollution should be taken into account, such as focus on solving the sulfur, carbon gases and water.

\section{References}

1. Liao, Z.Y.: Industrial Construction General Graphic Design. China Building Industry Press, Beijing (1982) (in Chinese)

2. The preparation group: Steel mills general plan reference, Metallurgical Industry Press, Beijing (1978) (in Chinese)

3. Sun, X.Q.: Systematic Layout Planning of Logistics Center Design. Science and Technology Theory and Management 10, 117-119 (2005)

4. Liu, G.F., Chen, X.L.: Systematic Layout Planning in the production system optimization, vol. 3, pp. 125-128 (2008) 